This information is current as of April 26, 2023.

\title{
Neuroimaging of Diving-Related Decompression Illness: Current Knowledge and Perspectives
}

J. Kamtchum Tatuene, R. Pignel, P. Pollak, K.O. Lovblad, A. Kleinschmidt and M.I. Vargas

AJNR Am J Neuroradiol 2014, 35 (11) 2039-2044

doi: https://doi.org/10.3174/ajnr.A4005

http://www.ajnr.org/content/35/11/2039 


\title{
Neuroimaging of Diving-Related Decompression Illness: Current Knowledge and Perspectives
}

\author{
J. Kamtchum Tatuene, R. Pignel, P. Pollak, K.O. Lovblad, A. Kleinschmidt, and M.I. Vargas
}

\begin{abstract}
SUMMARY: Diving-related decompression illness is classified into 2 main categories: arterial gas embolism and decompression sickness. The latter is further divided into types 1 and 2, depending on the clinical presentation. MR imaging is currently the most accurate neuroimaging technique available for the detection of brain and spinal cord lesions in neurologic type 2 decompression sickness. Rapid bubble formation in tissues and the bloodstream during ascent is the basic pathophysiologic mechanism in decompression illness. These bubbles can damage the central nervous system through different mechanisms, namely arterial occlusion, venous obstruction, or in situ toxicity. Neuroimaging studies of decompression sickness have reported findings associated with each of these mechanisms: some typical results are summarized and illustrated in this article. We also review the limitations of previous work and make practical methodologic suggestions for future neuroimaging studies.
\end{abstract}

$\mathrm{T}$ he term "decompression illness" encompasses all clinical manifestations induced by a rapid decrease of environmental pressure, sufficient to cause the formation of inert gas bubbles previously loaded within tissues or blood as a soluble phase. This can occur in various circumstances, including ascent from diving, flying or climbing mountains immediately after a dive, and exercising in hyperbaric/hypobaric chambers. ${ }^{1-3}$ Diving-related decompression illness is classified into 2 main categories: arterial gas embolism due to pulmonary decompression barotrauma and decompression sickness. ${ }^{4}$ There are 2 clinically defined types of decompression sickness. Type 1 refers to relatively mild symptoms such as joint pain, skin marbling, small patchy hemorrhages, and lymphatic obstruction. Conversely, type 2 includes more serious and often life-threatening symptoms and can be further divided into 4 subtypes or syndromes according to the organ affectednamely the brain, spinal cord, inner ear, or lung. ${ }^{5,6}$ Spinal cord lesions represent the majority of central nervous system insults associated with type 2 decompression sickness. ${ }^{7-9}$

Among the imaging modalities available to study neurologic

From the Neurology Division (J.K.T., P.P., A.K.), Department of Clinical Neurosciences; Hyperbaric Medicine Centre (R.P.), Department of Emergency Medicine; and Neuroradiology Division (K.O.L., M.I.V.), Department of Imaging and Medical Information Sciences, Geneva University Hospitals, Geneva, Switzerland.

Please address correspondence to Maria Isabel Vargas, MD, Geneva University Hospitals, Division of Neuroradiology, DISIM, Rue Gabrielle-Perret-Gentil 4, 1211 Genève 14, Switzerland; e-mail: Maria.I.Vargas@hcuge.ch

- Indicates open access to non-subscribers at www.ajnr.org

Indicates article with supplement on-line table.

http://dx.doi.org/10.3174/ajnr.A4005 type 2 decompression sickness, MR imaging clearly appears to be the most accurate for detecting pathologic changes in the brain and spinal cord. ${ }^{7,10}$ To date, several MR imaging studies of neurologic type 2 decompression sickness have been reported with different and often controversial results regarding the sensitivity and utility of this technique in patient evaluation and management. ${ }^{8,11-16}$ These discrepancies could be explained by lack of standardized imaging protocols, variable delays between symptom onset and image acquisition, and the high variability of the study design and technical devices. Our aim here is to provide a comprehensive review of neuroimaging studies of neurologic type 2 decompression sickness, discuss their limitations, and make proposals that could help improve the quality of future clinicoradiologic studies in the field.

\section{Imaging Findings and Related Pathophysiologic Theories}

The fundamental reason why decompression illness occurs is that during ascent from depth, gas bubbles form more rapidly in tissues and the bloodstream than the body can eliminate through diffusion and perfusion processes. ${ }^{8}$ At this point, some basic physics principles will help in understanding the mechanism of bubble formation. With increasing depth, the pressure of the air found in pulmonary alveoli increases because of compression at relatively constant temperature as stated by Boyle's law. Therefore, the partial pressure of nitrogen in pulmonary alveoli also increases according to Dalton's law. This change leads to an increase in nitrogen diffusion into the blood through the alveoli membrane according to Henry's principle of soluble gas pressure equilibration on either side of a permeable membrane. With time, 


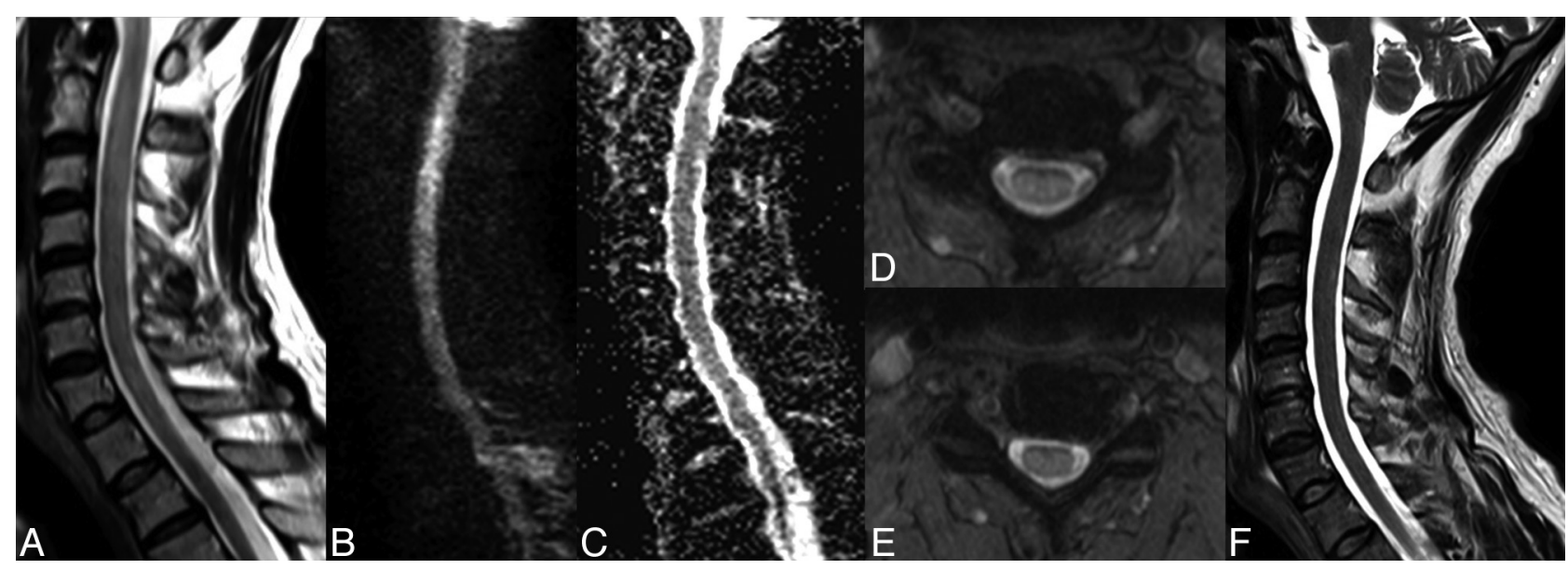

FIG 1. Reversible cervical spinal cord lesion due to decompression sickness. MR imaging shows an extensive lesion causing enlargement of the cervical spinal cord. The lesion appears as a high signal on sagittal $(A)$ and axial T2WI (D and $E)$ and on DWI $(B)$ without concomitant signal decrease on the ADC map (C). All these characteristics, with complete healing without a scar as shown on sagittal T2WI $(F)$ obtained 2 weeks later, are consistent with vasogenic edema (referred to as an "ischemic-like" lesion in the On-line Table).

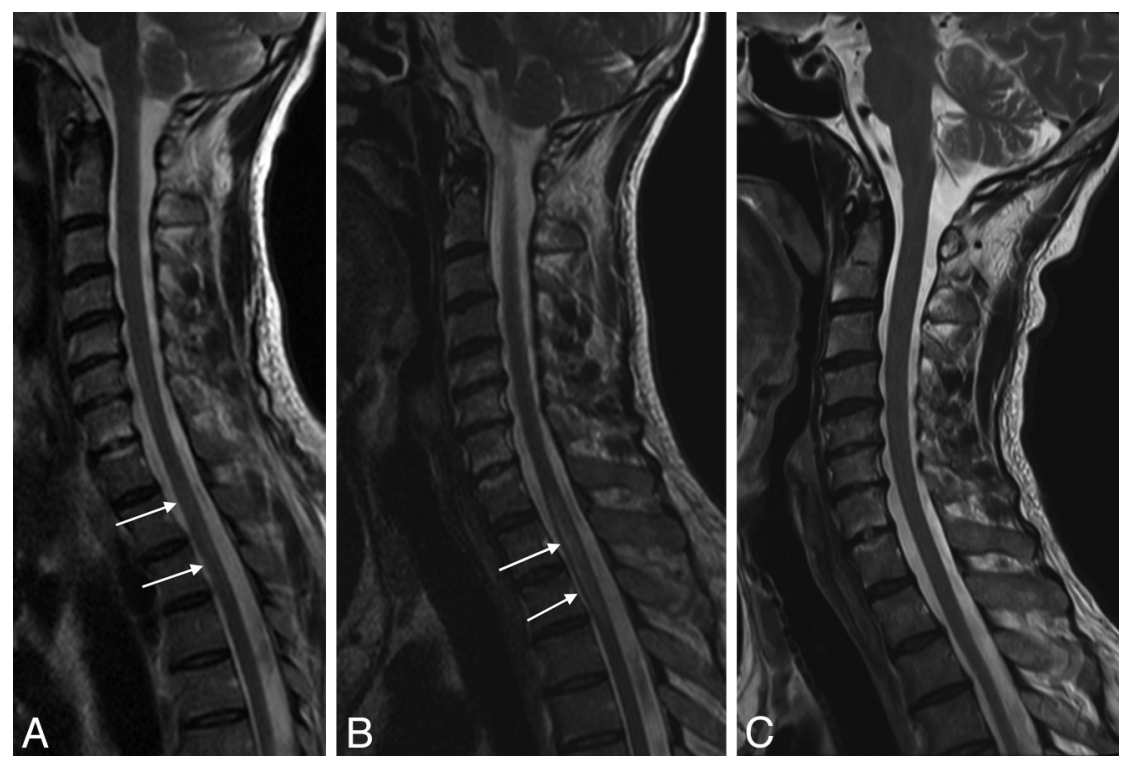

FIG 2. Reversible thoracic spinal cord lesion due to decompression sickness. MR imaging performed 24 hours after the diving accident shows a thoracic lesion appearing as a high signal on sagittal T2WI ( $A$, white arrows). The lesion increases in size on the following day ( $B$, white arrows) and subsequently disappears on day $13(C)$. This evolution may also be consistent with edema.

increasing amounts of nitrogen dissolve and accumulate in lipid components of tissues. As a diver ascends, there is a sequential well-orchestrated release of the nitrogen dissolved in tissues and blood. The nitrogen in the alveoli expands first and is eliminated; then, the nitrogen in blood is eliminated and its partial pressure in blood decreases, thus allowing saturated tissues to release nitrogen back into the bloodstream for subsequent pulmonary elimination. During fast ascents, the process of progressive nitrogen release does not take place properly and there is premature expansion of the nitrogen trapped in tissues and blood, leading to excessive bubble formation and subsequent tissue damage. ${ }^{1,17}$

The critical role of nitrogen bubbles in tissue damage is highly supported by some typical radiologic findings. First, the high-fat content of the myelin sheath with high solubility of nitrogen in fat explains the preponderance of white matter lesions either in the brain or the spine of patients with neurologic decompression illness
(Figs 1, 2, and 3A). Second, in spinal cord decompression sickness, there is predominant involvement of the thoracic cord segments (Figs 2 and 3B), which may be explained by the following: 1) their high fat content, allowing high concentrations of nitrogen during diving, especially in the lateral and posterior columns $s^{5,7,14,15}$; and 2) their relatively low mobility and blood flow, responsible for poor nitrogen bubble washout during ascent and hence a higher risk of ischemia. ${ }^{18-20}$

The exact mechanism through which nitrogen bubbles cause brain and spine damage is still highly debated, and there are currently 3 theories supporting 3 different pathophysiologic mechanisms: arterial occlusion, venous infarction, and in situ nitrogen toxicity. The following support the arterial occlusion theory: 1) the predominance of cerebral lesions in arterial gas embolisms with usually a clinical and radiologic stroke-like presentation (restricted diffusion appearing as hyperintensity on DWI with low values on the ADC map, high signal on T2WI, and usually no contrast enhancement) (Fig $3 A)^{7,21,22} 2$ ) The finding that nitrogen bubbles can interrupt arterial blood supply to the brain and spine either by direct obstruction of small capillaries or by activation of pathologic clotting at the blood-bubble interface. ${ }^{23-26}$ This effect on clotting is increased in case of low hematocrit, explaining the higher risk of severe cardiopulmonary and neurologic decompression sickness in dehydrated divers. ${ }^{27-30} 3$ ) The higher prevalence of a patent foramen ovale in patients experiencing decompression illness $^{31-39}$ could favor paradoxic embolization of either nitrogen bubbles or pathologically formed thrombi with subsequent ischemic infarcts in the brain ${ }^{40}$ or spine, where the collateral circulation network is less robust. ${ }^{41} 4$ ) The presence of extensive gray matter lesions in some neurologic decompression sickness cases - gray matter lesions being typically seen in arterial 


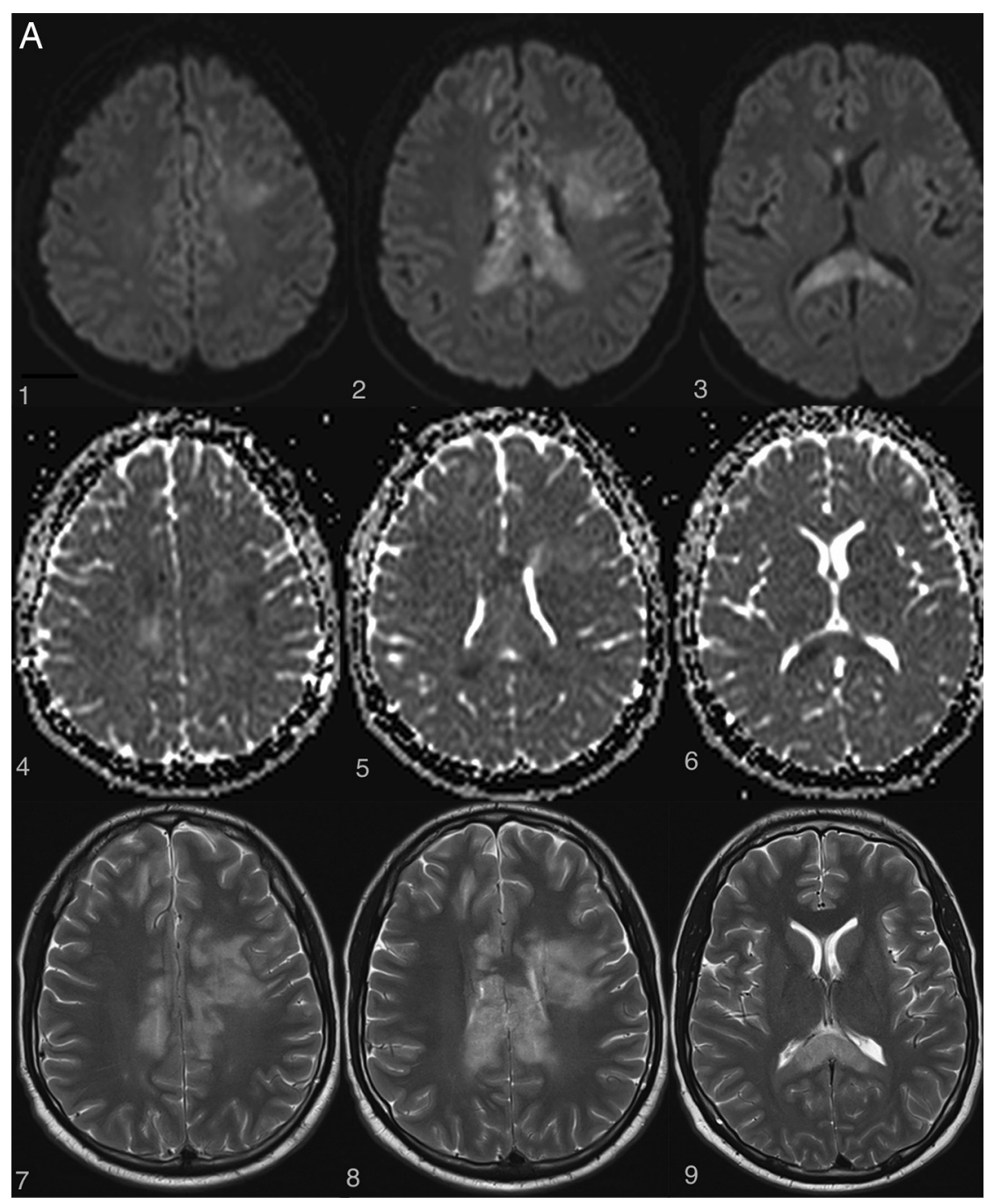

FIG 3. Examples of irreversible brain and spinal cord lesions due to decompression sickness $(A, B$, and $C$ are taken from the same patient). $A$, On DWI $(1,2,3,4,5,6)$, the areas of restricted diffusion correspond to lesions of the corpus callosum and frontal white matter on both sides. They appear as high signal on T2WI $(7,8,9)$. B, Sagittal (1 and 2, white arrows) and axial ( 3 and 4, white arrows) T2WI shows a cervicothoracic (C7-T) lesion appearing as high signal without contrast enhancement on TTWI (2). C, On follow-up I month later, the lesions described in $A$ and $B$ are still present on these brain $(1,2,3,4)$ and spine $(5,6)$ images. Note the enhancement of the corpus callosum ( 3 and 4$)$. Lesions of the right frontal deep white matter and corpus callosum have healed and now appear as "little cavities." Similar features are usually seen in ischemic or necrotic lesions of the central nervous system.

infarction processes. ${ }^{11,18,42}$ 5) Hypoperfused areas compatible with embolic cerebral arterial occlusion are observed in some patients with decompression illness when using SPECT with hexamethylpropyleneamine oxime (HMPAO) marked with a metastable nuclear isomer of the radioisotope technetium Tc99m (the product is sometimes referred to as exametazime). ${ }^{43,44}$

On the other hand, various radiologic and histopathologic findings have been published to support the venous infarction theory. First, the more frequent occurrence of lateral and posterior column white matter lesions compared with gray matter lesions in spinal cord decompression sickness is more likely a consequence of an obstruction of the slow-flowing epidural venous bed by nitrogen bubbles, which leads to vasogenic edema (Figs 1 and 2). ${ }^{5,8}$ In some cases, there may be additional venous infarction (Fig 3B, -C). Similar lesions have been provoked experimentally in dogs. ${ }^{9}$ Second, several histopathologic studies have dem- onstrated venous obstruction and white matter congestion. ${ }^{45,46}$ Third, vasogenic edema, appearing as high signal on both DWI and ADC maps, was observed by Vollmann et al in $2011^{47}$ in a case of spinal cord decompression sickness, also suggesting a venous rather than arterial pathologic process.

The third theory of in situ nitrogen toxicity is more speculative and posits that nitrogen bubbles found in intercellular spaces may have a direct toxic effect on neurons, causing alterations of the electrical properties of membranes and impairment of ion flow regulation with subsequent cytotoxic edema and cell death. Areas of necrosis may be viewed as highsignal lesions on T2WI and as low signal on T1WI. Additionally, bubbles within the myelin sheath might cause alterations of nerve conduction. This theory of in situ nitrogen toxicity, also called the "autochthonous theory," ${ }^{14}$ may, at least partially, explain symptoms recorded in patients with type 1 decompression sickness, nitrogen narcosis, and type 2 decompression sickness without objective abnormalities on brain or spine MR imaging. ${ }^{48,49}$

Authors of MR imaging studies of decompression illness frequently report that the different clinicoradiologic patterns mentioned above overlap in the same patient, thereby suggesting that no single unifying pathophysiologic mechanism could completely explain this complex condition. ${ }^{14,16,47}$ Some have argued that there is a greater participation of arterial occlusion in brain lesions because they are more frequently described in cases of arterial gas embolism, while venous occlusion may play a greater role in spine lesions and may even be favored by local me- chanical cord compression. ${ }^{11,15}$ Whatever the preponderant mechanism involved, the treatment is urgent hyperbaric therapy to allow nitrogen to dissolve and be expelled via the lungs.

Some general rules have been derived from available MR imaging studies. First, any time a lesion is found on radiologic images, there is good correspondence with the clinical symptoms or syndromes described. ${ }^{8,11}$ Second, normal MR imaging findings of the spinal cord do not rule out a diagnosis of decompression illness. ${ }^{15,50,51}$ Third, in regard to evolution and prognosis, clinicoradiologic discrepancies have been observed (either worsening of lesions on MR imaging despite clinical improvement as shown in Fig 2 or improvement in MR imaging lesions despite neurologic deterioration $^{19}$ ). Furthermore, patients with hemorrhagic cord injury have the worst neurologic outcome; patients with mere spinal cord edema do better; and patients with normal-appearing spinal cords 

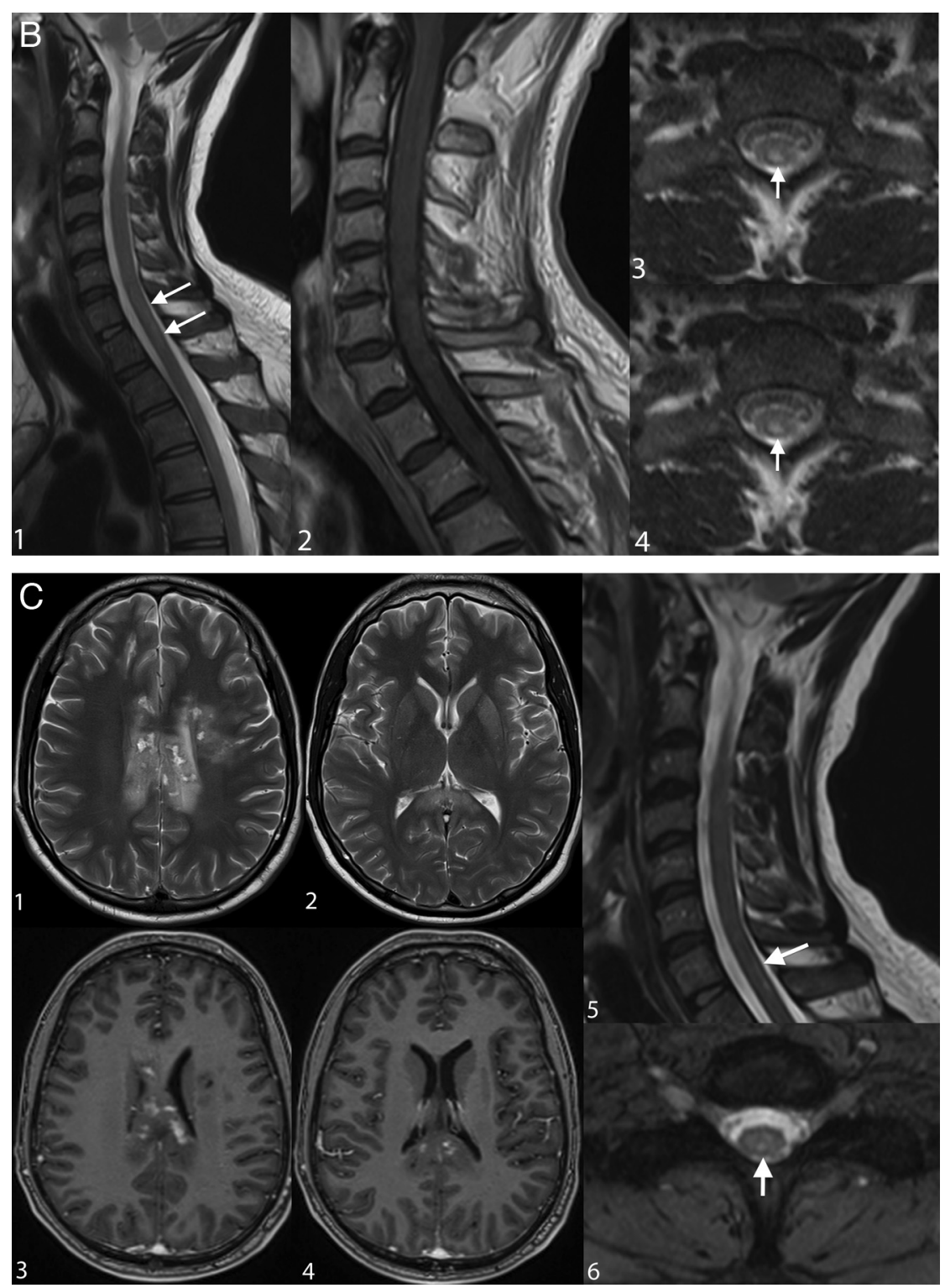

FIG 3. Continued.

consistently have a good outcome, though the lack of signal abnormalities on MR imaging does not necessarily mean that the patient will not develop sequelae because the negative predictive value of an investigation with normal findings is $77 \% .^{15,16,52}$

Anecdotal findings have been reported in patients with decompression illness. These include intracranial hemorrhages ${ }^{53}$ and extensive gas inclusions in CSF spaces. ${ }^{54}$ The On-line Table gives an overview of the major characteristics of lesions most frequently found on MR imaging in type 2 decompression sickness.

\section{Critical Appraisal of Available Imaging Studies and Suggested Future Directions}

To date, all neuroimaging studies have reported the low sensitivity of MR imaging for detecting central nervous system lesions in patients with decompression sickness. ${ }^{8,11,49}$ This could be explained, in part, by the delay between the diving accident and the imaging study because urgent hyperbaric recompression therapy is the priority. The latter could reverse signal alterations in the brain or spine, which then would not be depicted by posttreatment imaging.

However, several other limitations of available studies could have had a negative impact on the ability to detect central nervous system lesions. First, none of those studies have used high-field magnets (3T). Most of the authors used a 1.5T system, ${ }^{11,47,49,55}$ and some even used a $0.5 \mathrm{~T}$ system, which has a very low sensitivity. ${ }^{8,56}$ Second, with the exception of Vollmann et al, ${ }^{47}$ no previously published MR imaging studies of decompression sickness used DWI and ADC maps. The use of these sequences could conceivably increase MR imaging sensitivity and even provide additional data on the pathophysiology of brain damage in divers. The same is true for DTI, which has been used only once in animal models of decompression sickness. ${ }^{57}$ The third limitation is that only one ${ }^{56}$ of the previous MR imaging studies included systematic imaging of both brain and spine. This is probably because they were all retrospective studies in which the part of the central nervous system explored was chosen in accordance with the clinical syndrome. Because subclinical brain lesions have been reported in decompression sickness, ${ }^{58}$ we think that the predominance of symptoms and signs related to spinal cord lesions could have obscured the possibility of brain damage, thus leading to underestimation of the overall prevalence of central nervous system lesions, with a negative impact on MR imaging sensitivity.

Taking into consideration all the aforementioned methodologic limitations, we would recommend using higher field strengths ( 1.5 or 3T) and, systematically, joint brain and spine imaging in future MR imaging studies of decompression illness. We tentatively suggest the following imaging protocol for the brain: T1WI, T2WI, FLAIR, gradient-echo, DWI and ADC mapping, and contrastenhanced T1WI. For spinal cord exploration, we would recommend the following sequences: sagittal fast spin-echo T2 and spinecho T1 in the acute phase without and with contrast medium, which may be very useful in the subacute phase. We also encourage clinicians and radiologists to use more sophisticated techniques such as DTI, which could provide deeper insight into pathophysiologic processes.

Some authors have tried to identify prognostic factors in decompression sickness. ${ }^{59,60}$ They have even proposed a prospectively validated clinical prognostic score ${ }^{61-64}$ Added to that, the prognostic value of MR imaging findings has been independently evaluated, though in spinal cord decompression sickness only. ${ }^{15,16}$ However, there is currently no available study that tried 
to integrate neuroimaging findings into a prognostic score. Moreover, the importance of serial brain and spine imaging in the follow-up of patients with decompression sickness has not been studied. Such serial imaging could be used in comparative evaluations of the various treatment protocols currently available because there is no consensus on which is the best. ${ }^{65}$

\section{CONCLUSIONS}

Several neuroimaging studies of decompression illness have been conducted during the past decades. They have helped identify the spectrum of central nervous system lesions in neurologic decompression sickness and have provided useful data for understanding the related possible pathophysiologic mechanisms. However, due to technical and methodologic limitations of the available studies, many questions remain unanswered, especially those pertaining to the role of MR imaging in evaluating treatment protocols and estimating prognosis. Therefore, it seems obvious that well-designed prospective studies integrating new imaging techniques and better designed protocols should be conducted to explore these aspects and eventually provide data that help improve the management of patients with decompression illness.

Disclosures: Andreas Kleinschmidt-UNRELATED: Other: Senior Editor for the journal Neuroimage (Elsevier).

\section{REFERENCES}

1. Elliott DH, Moon RE. Manifestations of the Decompression Disorders: The Physiology and Medicine of Diving. 4th ed. London: Saunders; 1993:481

2. Faralli F. Decompression illness. In: Oriani G, Marroni A, Wattel F, eds. Handbook on Hyperbaric Medicine. Berlin: Springer-Verlag; 1996:135-82

3. Pulley SA. Decompression sickness. Medscape. 2012 (updated June 14, 2012). http://emedicine.medscape.com/article/769717-overview. Accessed December 2, 2013

4. Melamed Y, Shupak A, Bitterman H. Medical problems associated with underwater diving. $N$ Engl J Med 1992;326:30-35

5. Manabe Y, Sakai K, Kashihara K, et al. Presumed venous infarction in spinal decompression sickness. AJNR Am J Neuroradiol 1998; 19:1578-80

6. Newton HB. Neurologic complications of scuba diving. Am Fam Physician 2001;63:2211-18

7. Warren LP Jr, Djang WT, Moon RE, et al. Neuroimaging of scuba diving injuries to the CNS. AJR Am J Roentgenol 1988;151:1003-08

8. Sparacia G, Banco A, Sparacia B, et al. Magnetic resonance findings in scuba diving-related spinal cord decompression sickness. MAGMA 1997;5:111-15

9. Hallenbeck JM, Bove AA, Elliott DH. Mechanisms underlying spinal cord damage in decompression sickness. Neurology 1975;25:308-16

10. Hodgson M, Beran RG, Shirtley G. The role of computed tomography in the assessment of neurologic sequelae of decompression sickness. Arch Neurol 1988;45:1033-35

11. Reuter M, Tetzlaff $K$, Hutzelmann A, et al. MR imaging of the central nervous system in diving-related decompression illness. Acta Radiol 1997;38:940-44

12. Yanagawa $\mathrm{Y}$, Okada $\mathrm{Y}$, Terai $\mathrm{C}$, et al. MR imaging of the central nervous system in divers. Aviat Space Environ Med 1998;69:892-95

13. Hutzelmann A, Tetzlaff $K$, Reuter $M$, et al. Does diving damage the brain? MR control study of divers' central nervous system. Acta Radiol 2000;41:18-21

14. Kei PL, Choong CT, Young T, et al. Decompression sickness: MRI of the spinal cord. J Neuroimaging 2007;17:378-80

15. Gempp E, Blatteau JE, Stephant E, et al. MRI findings and clinical outcome in $\mathbf{4 5}$ divers with spinal cord decompression sickness. Aviat Space Environ Med 2008;79:1112-16

16. Hennedige T, Chow W, Ng YY, et al. MRI in spinal cord decompression sickness. J Med Imaging Radiat Oncol 2012;56:282-88

17. McMullin AM. Scuba diving: What you and your patients need to know. Cleve Clin J Med 2006;73:711-12, 714, 716 passim

18. Aharon-Peretz J, Adir Y, Gordon CR, et al. Spinal cord decompression sickness in sport diving. Arch Neurol 1993;50:753-56

19. Yoshiyama M, Asamoto S, Kobayashi N, et al. Spinal cord decompression sickness associated with scuba diving: correlation of immediate and delayed magnetic resonance imaging findings with severity of neurologic impairment: a report on 3 cases. Surg Neurol 2007;67:283-87

20. Hierholzer J, Tempka A, Stroszczynski C, et al. MRI in decompression illness. Neuroradiology 2000;42:368-70

21. Moon RE. Gas embolism. In: Oriani G, Marroni A, Wattel F, eds. Handbook on Hyperbaric Medicine. Berlin: Springer-Verlag; 1996:229

22. Leitch DR, Green RD. Pulmonary barotrauma in divers and the treatment of cerebral arterial gas embolism. Aviat Space Environ Med 1986;57(10 pt 1):931-38

23. Hjelde A, Bergh K, Brubakk AO, et al. Complement activation in divers after repeated air/heliox dives and its possible relevance to DCS. J Appl Physiol 1995;78:1140-44

24. Huang KL, Lin YC. Activation of complement and neutrophils increases vascular permeability during air embolism. Aviat Space Environ Med 1997;68:300-05

25. Dufka AJ, Francis TJ. Pathophysiology of decompression sickness. In: Bove AA, ed. Diving Medicine. 3rd ed. Philadelphia: Saunders; 1997:159-75

26. Boussuges A, Succo E, Juhan-Vague I, et al. Activation of coagulation in decompression illness. Aviat Space Environ Med 1998;69:129-32

27. Fahlman A, Dromsky DM. Dehydration effects on the risk of severe decompression sickness in a swine model. Aviat Space Environ Med 2006;77:102-06

28. Williams ST, Prior FG, Bryson P. Hematocrit change in tropical scuba divers. Wilderness Environ Med 2007;18:48-53

29. Newton HB, Burkart J, Pearl D, et al. Neurological decompression illness and hematocrit: analysis of a consecutive series of 200 recreational scuba divers. Undersea Hyperb Med 2008;35:99-106

30. Gempp E, Blatteau JE, Pontier JM, et al. Preventive effect of pre-dive hydration on bubble formation in divers. Br J Sports Med 2009; 43:224-28

31. Germonpré P, Dendale P, Unger P, et al. Patent foramen ovale and decompression sickness in sports divers. J Appl Physiol 1998; 84:1622-26

32. Bove AA. Risk of decompression sickness with patent foramen ovale. Undersea Hyperb Med 1998;25:175-78

33. Wilmshurst PT, Nightingale S, Walsh KP, et al. Effect on migraine of closure of cardiac right-to-left shunts to prevent recurrence of decompression illness or stroke or for haemodynamic reasons. Lancet 2000;356:1648-51

34. Schwerzmann M, Seiler C. Recreational scuba diving, patent foramen ovale and their associated risks. Swiss Med Wkly 2001;131:365-74

35. Schwerzmann M, Seiler C, Lipp E, et al. Relation between directly detected patent foramen ovale and ischemic brain lesions in sport divers. Ann Int Med 2001;134:21-24

36. Cartoni D, De Castro S, Valente G, et al. Identification of professional scuba divers with patent foramen ovale at risk for decompression illness. Am J Cardiol 2004;94:270-73

37. Torti SR, Billinger M, Schwerzmann M, et al. Risk of decompression illness among $\mathbf{2 3 0}$ divers in relation to the presence and size of patent foramen ovale. Eur Heart J 2004;25:1014-20

38. Harrah JD, O'Boyle PS, Piantadosi CA. Underutilization of echocardiography for patent foramen ovale in divers with serious decompression sickness. Undersea Hyperb Med 2008;35:207-11

39. Koch AE, Kirsch $H$, Reuter M, et al. Prevalence of patent foramen ovale (PFO) and MRI-lesions in mild neurological decompression sickness (type B-DCS/AGE). Undersea Hyperb Med 2008;35:197-205 
40. Palmer AC, Calder IM, Yates PO. Cerebral vasculopathy in divers. Neuropathol Appl Neurobiol 1992;18:113-24

41. Mastaglia FL, McCallum RI, Walder DN. Myelopathy associated with decompression sickness: a report of six cases. Clin Exp Neurol 1983;19:54-59

42. McCormac J, Mirvis SE, Cotta-Cumba C, et al. Spinal myelopathy resulting from decompression sickness: MR findings in a case and review of the literature. Emerg Radiol 2002;9:240-42

43. Macleod MA, Adkisson GH, Fox MJ, et al. 99Tcm-HMPAO single photon emission tomography in the diagnosis of cerebral barotrauma. Br J Radiol 1988;61:1106-09

44. Adkisson GH, Macleod MA, Hodgson M, et al. Cerebral perfusion deficits in dysbaric illness. Lancet 1989;2:119-22

45. Royon M, Wolkiewiez J. Bilan scanographique et phlébographique d'un accident médullaire de décompression. Med Sub Hyp 1987; 4:117-20

46. Kim RC, Smith HR, Henbest ML, et al. Nonhemorrhagic venous infarction of the spinal cord. Ann Neurol 1984;15:379-85

47. Vollmann R, Lamperti M, Magyar M, et al. Magnetic resonance imaging of the spine in a patient with decompression sickness. Clin Neuroradiol 2011;21:231-33

48. Levin HS, Goldstein FC, Norcross K, et al. Neurobehavioral and magnetic resonance imaging findings in two cases of decompression sickness. Aviat Space Environ Med 1989;60:1204-10

49. Grønning M, Risberg J, Skeidsvoll H, et al. Electroencephalography and magnetic resonance imaging in neurological decompression sickness. Undersea Hyperb Med 2005;32:397-402

50. Tournebise H, Boucand MH, Landi J, et al. Paraplegia and decompression sickness. Paraplegia 1995;33:636-39

51. Colineau X, Muyard B, Paoletti H, et al. Accidents neurologiques de décompression: mise en évidence par IRM. Med Armees 1998; 26:371-79

52. White ML, El-Khoury GY. Neurovascular injuries of the spinal cord. Eur J Radiol 2002;42:117-26
53. Josefsen R, Wester K. Cerebellar hemorrhage: a rare, but serious complication in decompression disease [in Norwegian]. Tidsskr Nor Laegeforen 1999;119:3901-02

54. Ozdoba C, Weis J, Plattner T, et al. Fatal scuba diving incident with massive gas embolism in cerebral and spinal arteries. Neuroradiology 2005;47:411-16

55. Gao GK, Wu D, Yang Y, et al. Cerebral magnetic resonance imaging of compressed air divers in diving accidents. Undersea Hyperb Med 2009;36:33-41

56. Todnem K, Nyland H, Skeidsvoll H, et al. Neurological long term consequences of deep diving. Br J Ind Med 1991;48:258-66

57. Hutchinson EB, Sobakin AS, Meyerand ME, et al. Diffusion tensor MRI of spinal decompression sickness. Undersea Hyperb Med 2013;40:23-31

58. Aksoy FG. MR imaging of subclinical cerebral decompression sickness: a case report. Acta Radiol 2003;44:108-10

59. Dick AP, Massey EW. Neurologic presentation of decompression sickness and air embolism in sport divers. Neurology 1985;35:667-71

60. Ball R. Effect of severity, time to recompression with oxygen, and re-treatment on outcome in forty-nine cases of spinal cord decompression sickness. Undersea Hyperb Med 1993;20:133-45

61. Boussuges A, Thirion X, Blanc P, et al. Neurologic decompression illness: a gravity score. Undersea Hyperb Med 1996;23:151-55

62. Gempp E, Blatteau JE. Risk factors and treatment outcome in scuba divers with spinal cord decompression sickness. J Crit Care 2010;25:236-42

63. Blatteau JE, Gempp E, Constantin P, et al. Risk factors and clinical outcome in military divers with neurological decompression sickness: influence of time to recompression. Diving Hyperb Med 2011;41:129-34

64. Blatteau JE, Gempp E, Simon O, et al. Prognostic factors of spinal cord decompression sickness in recreational diving: retrospective and multicentric analysis of 279 cases. Neurocrit Care 2011;15:120-27

65. Moon RE, Gorman DF. Treatment of decompression disorders. In: Bennett PB, Elliott DH, eds. The Physiology and Medicine of Diving. 4th ed. London: WB Saunders; 1993:506-41 